\title{
Coccocypselum lanceolatum (Rubiaceae): nova espécie hospedeira de Puccinia lateritia no B rasil
}

\author{
M eiriele da Silva ${ }^{1}$ e Olinto Liparini Pereira ${ }^{1 *}$
}

Departamento de Fitopatologia, U niversidade Federal de Viçosa, CEP 36570-000, Viçosa, M G.; *A utor para correspondência: Olinto Liparini Pereira; e-mail: oliparini@ufv.br

Data de chegada: 30/01/2007. A ceito para publicação em: 18/08/2007

Coccocypselum lanceolatum (R uiz e Pav.) Pers. é uma planta herbácea, perene, prostrada, pertencente à família Rubiaceae e caracteriza-se pela presença de indumento velutino em suas folhas, inflorescências pedunculadas e cálice reflexo (Pereira et al ., A cta bot. bras. 20:207-224, 2006). No B rasil, essa espécie vegetal encontra-se distribuída desde M inas Gerais até o Rio Grande do Sul (Smith \& Downs, Sellowia 7: 13-86, 1956).

Plantas de $C$. lanceolatum apresentando sintomas de ferrugem (Figura $1 \mathrm{~A}$ ) foram encontradas no sub-bosque da trilha do Totem D eitado no Parque Estadual da Serra do B rigadeiro (PESB ). 0 material foi encaminhado ao Laboratório de M icologia/D epartamento de Fitopatologia/UFV e as estruturas do patógeno foram montadas em lactofenol. 0 fungo possuía as seguintes características morfológicas: lesões escuras correspondentes às pústulas de teliósporos de 1,0-7,5 $\mathrm{mm}$ de diâmetro, localizados na superfície abaxial das folhas. Télio irrompente, castanho-escuro, 135-589 $\mu \mathrm{m}$ de diâmetro, compacto. Teliósporos bicelulares (Figura 1B), elipsóides, lisos, de coloração castanha, 16-25 $\mu \mathrm{m}$ larg. x 22-32 $\mu \mathrm{m}$ compr. e de parede espessa. Pedicelos hialinos, persistentes, de parede fina, 1,5-6,0 $\mu \mathrm{m}$ larg. $x$ 25,0-69,0 ㅆm compr. Espermogônio, écio e uredínio ausentes, mesósporos raros. Material examinado sobre Coccocypselum lanceolatum (Ruiz e Pav.) Pers. (Rubiaceae), Brasil, M inas Gerais, município deA raponga, Parque Estadual da Serra do B rigadeiro (PESB), trilha do Totem Deitado, 27.V II.2006, 0 .L. Pereira s.n. (VIC 30432). Deacordo com as características morfológicas, o fungo foi identificado como Puccinia lateritia (Berk. \& M. A . Curtis) Lageh.

No B rasil, $P$. lateritia é relatada em: Bor reria sp., D iodia prostrata Sw., Diodia radula (Willd. \& Hoffmanns. ex Roem. \& Schult.) Cham. $\&$ Schltdl., Diodia rigida Cham. \& Schltdl., D iodia teres Walter, Diodia sp., Hemidiodia sp., Spermacoce latifolia A ubl., Spermacoce ocymoides Burm. f., Spermacoce verticillata L. e Spermacoce sp. [H ennen et al., Catalogue of the species of plant rust fungi (U redinales) of Brazil, 2005]. R elatos na literatura listam a ocorrência de P. lateritia em diversos gêneros hospedeiros da família Rubiaceae, entretanto associado ao gênero Coccocypselum, há um único relato na espécie $C$. histutum Bartl. ex DC. na Costa Rica (A rthur, M ycologia 10:111-154, 1918). Portanto, esse é o primeiro relato de $P$. lateritia associada ao gênero Coccocypselum no Brasil.

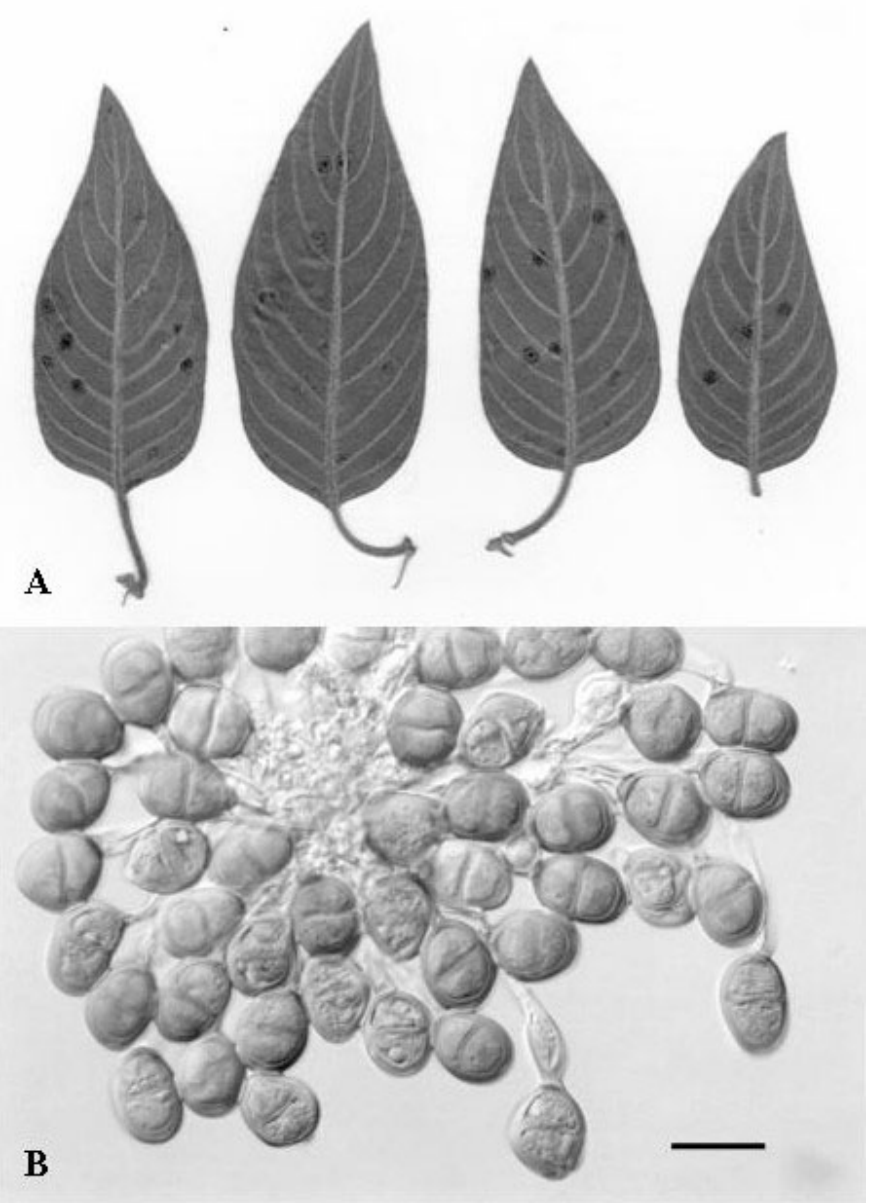

Figura 1. Puccinia lateritia. A . sintoma de ferrugem na superfície abaxial de Coccocypselum lanceolatum; B. Teliósporos bicelulados. B arra $=25 \mu \mathrm{m}(B)$.

A gradecimentos ao botânico Gilmar E. Valente do D epartamento de B iologia Vegetal/U FV pela identificação da espécie hospedeira. 